\title{
Impacts of Methyl Farnesoate and 20-Hydroxyecdysone on Larval Mortality and Metamorphosis in the Kuruma Prawn Marsupenaeus japonicus
}

\author{
Kenji Toyota ${ }^{1,2 *}$, Fumihiro Yamane ${ }^{3}$ and Tsuyoshi Ohira ${ }^{1 *}$ \\ ${ }^{1}$ Department of Biological Sciences, Faculty of Science, Kanagawa University, Kanagawa, Japan, ${ }^{2}$ Department of Biological \\ Science and Technology, Faculty of Industrial Science and Technology, Tokyo University of Science, Tokyo, Japan, ${ }^{3}$ Mie \\ Prefectural Fish Farming Center, Shima, Japan
}

OPEN ACCESS

Edited by:

Marcy N. Wilder,

Japan International Research Center for Agricultural Sciences

(JIRCAS), Japan

Reviewed by:

Andreas Heyland University of Guelph, Canada

Cameron John Hyde,

University of the Sunshine

Coast, Australia

*Correspondence: Kenji Toyota megabass0719@yahoo.co.jp

Tsuyoshi Ohira ohirat-bio@kanagawa-u.ac.jp

Specialty section: This article was submitted to Experimental Endocrinology,

a section of the journal

Frontiers in Endocrinology

Received: 15 April 2020

Accepted: 17 June 2020

Published: 28 July 2020

Citation:

Toyota K, Yamane F and Ohira T (2020) Impacts of Methyl Farnesoate and 20-Hydroxyecdysone on Larval Mortality and Metamorphosis in the Kuruma Prawn

Marsupenaeus japonicus.

Front. Endocrinol. 11:475 doi: 10.3389/fendo.2020.00475
Physiological functions of juvenile hormone $(\mathrm{JH})$ and molting hormone have been demonstrated in insects. $\mathrm{JH}$, molting hormone and their mimics (insect growth regulators, IGRs) show endocrine-disrupting effects not only on target pest insects but also on other arthropod species such as crustaceans. However, little is known about the endocrine-disrupting effects of IGRs on benthic crustaceans. In this study, laboratory experiments were conducted to investigate effects of representative innate $\mathrm{JH}$ in crustaceans (methyl farnesoate, MF) and molting hormone (20-hydroxyecdysone, 20E, active form of ecdysteroid) on larval stages of the kuruma prawn Marsupenaeus japonicus, which is a decapod crustacean living in warm seawater. Larval development of kuruma prawn progresses in the order of nauplius, zoea, mysis, and then post-larvae with molting and metamorphosis, but it is unknown whether both MF and 20E have crucial roles in metamorphosis and molting of this species. Treatments of either MF or 20E on shrimp larvae were attempted at each developmental stage and those effects were validated. In terms of $\mathrm{EC}_{50}$ values between mortality and metamorphosis, there were apparent differences in the transition from nauplius to zoea (MF: 7.67 and $0.12 \mu \mathrm{M}$; 20E: 3.84 and $0.06 \mu \mathrm{M}$ in survival and metamorphic rates, respectively). In contrast, $\mathrm{EC}_{50}$ values in MF and 20E treatments showed high consistency in the transitions between zoea to mysis ( $\mathrm{EC}_{50}$ values for survival; MF: 1.25 and 20E: $0.22 \mu \mathrm{M}$ ), and mysis to post-larvae ( $E_{50}$ values for survival; MF: 0.65 and 20E: $\left.0.46 \mu \mathrm{M}\right)$. These data suggest that nauplius has strong resistance against exposure to MF and 20E. Moreover, both chemicals induced high mortality triggered by the disruption of molting associated with metamorphosis. To our knowledge, this is the first experimental evidence that investigates in vivo physiological functions of MF and $20 \mathrm{E}$ in the larval stages of kuruma prawn, shedding light on not only ecotoxicological impacts of IGRs released into nature, but also endocrine mechanisms underlying larval development with metamorphosis in benthic decapod crustaceans.

Keywords: crustacean, Penaeid, juvenile hormone, ecdysone, molting 


\section{INTRODUCTION}

Recent advances in arthropod phylogeny have revealed that the Crustacean clade is not monophyletic, and can be divided into three extant clades (Ostracoda, Malacostraca, Branchiopoda). A current hypothesis supports that the clade of Hexapoda (insect species) is nested within the Crustacea, which forms a new clade known as Pancrustacea, although its details are still controversial $(1,2)$. This finding has provided impetus into the belief that the comparative analysis of crustaceans and insects is indispensable to understanding the evolutionary origin of a range of characteristics that are believed to be insect-specific. Indeed, both crustaceans and insects share various fundamental traits such as endocrine-driven developmental and reproductive processes, which are regulated primarily by juvenile hormone (JH) and molting hormone (ecdysteroids).

Methyl farnesoate (MF) is thought to be the equivalent of $\mathrm{JH}$ in crustaceans. Previous studies have demonstrated that MF may play a similar role to $\mathrm{JH}$ in insects, by regulating molting, sexual maturation, and reproduction in concert with ecdysteroids, the main active form being 20hydroxyecdysone, or 20E (3-5). To date, the hormonal actions of MF and $20 \mathrm{E}$ are triggered by activation of the $\mathrm{JH}$ receptor (JHR) complex (methoprene-tolerant and steroid receptor coactivator) and ecdysone receptor complex (ecdysone receptor and ultraspiracle), respectively, which are the nuclear receptors responsible for transcriptional regulation of the aforementioned biological processes in crustaceans as well as insects (6-10). Based on those findings, endocrine-disrupting chemicals targeting the JHR and/or EcR have been designed and developed as insect growth regulators (IGRs) that disrupt metamorphosis and/or molting in pest arthropods resulting in the effective suppression of pest outbreaks $(11,12)$. However, due to highly conserved endocrine systems between insects and crustaceans, the environmental residues of these IGRs may also affect ecologically and economically important non-target species, such as aquatic crustaceans (e.g., prawns and crabs). Despite much earnest research to investigate the toxic effects of IGRs using tiny crustaceans such as water fleas, little is still known about endocrine-disrupting effects of IGRs on benthic crustaceans. This knowledge gap is largely due to a lack of established model crustacean species that can be applied for physiological and toxicological studies.

In Malacostracan crustaceans, the eyestalk neurosecretory system, which is referred to as the $\mathrm{X}$-organ-sinus gland complex, plays a pivotal role in larval development associated with molting and metamorphosis. However, the endocrine mechanisms underlying larval development are still largely unknown. Generally, biosynthesis and secretion of ecdysteroids are negatively regulated by molt-inhibiting hormone, and those of MF are also suppressively controlled by mandibular organinhibiting hormone (MOIH) secreted from the X-organ-sinus gland complex in eyestalks, indicating that both endogenous ecdysteroids and MF titers increase when both eyestalks were ablated $(13,14)$. Based on this knowledge, numerous studies found that eyestalk ablation of larvae resulted in the formation of larval intermediates in the blue crab (Callinectes sapidus) and the American lobster (Homarus americanus), and took place in extra-larval stages causing a consequent delay in metamorphosis in the mud crab (Rhithropanopeus harrisii), shrimps (Palaemon macrodactylus, Palaemonetes varians), and in the swimming crab (Portunus trituberculatus) (15) reviewed in (4). However, the mechanisms by which these hormones exert their effects remain poorly understood.

Kuruma prawn, Marsupenaeus japonicus, is a member of the family Penaeidae (Class Malacostraca, Order Decapoda), and is widely distributed from Japan and Southeast Asia to Western Pacific Oceans (16). Due to the economic importance of this species, annual catches have declined sharply since the 1990s (17). To overcome this situation, research into seed production of kuruma prawn, which was reared from eggs to juveniles that were then released into sea water to maintain natural populations, was conducted (18). Based on a long history of seed production of kuruma prawn, its larval developmental process is welldescribed. Nauplius larvae hatch about 13-14 h after ovulation at $27-29^{\circ} \mathrm{C}$, and repeat molting six times (stages I-VI) within $36 \mathrm{~h}$, resulting in metamorphosis to the zoea stage. Likewise, the zoea molts three times (stages I-III) within 4 days and metamorphoses into the mysis stage. Finally, the mysis molts three times (stages I-III) within 3 days and metamorphoses into the post-larval stage (4). Although 20E-driven ecdysteroid signaling pathways are known to regulate molting in crustaceans, less is known about the regulation of larval development and metamorphosis by MF and 20E. In this study, we treated kuruma prawn larvae at each developmental stage with either MF or 20E and validated toxic effects such as rates of mortality and metamorphosis.

\section{MATERIALS AND METHODS}

\section{Animals}

Sexually matured female kuruma prawns (M. japonicus) were purchased from a local fishery shop at a fishing port of Isshiki in Nishio City, Aichi Prefecture, Japan, in April 2018. All prawns were transferred to the Mie Prefectural Fish Farming Center (Mie, Japan) and all experiments were conducted there. Prawns were maintained in a tank with natural seawater at $24^{\circ} \mathrm{C}$ under natural daylight and fed daily with polychaeta worms as raw bait for 1 day prior to treatment of eyestalk ablation that stimulates ovarian maturation and then spawning within a few days. Newly hatched nauplius larvae (ca. 10,000 individuals), which were obtained from seven females, were transferred to a $100 \mathrm{~L}$ black tank with natural seawater at constant $24^{\circ} \mathrm{C}$ under natural daylight. The culture feed series of kuruma prawn larvae was as follows: from egg to zoea stage I (3 days after beginning) was the commercial diatom Chaetoceros gracilis (Pacific Trading Co., Ltd., Fukuoka, Japan); from zoea stage 2 to mysis stage I was both commercial diatom and a prawn diet (Vitalprawn: Higashimaru Co., Ltd., Kagoshima, Japan); thereafter, both the commercial prawn diet and nauplius Artemia larvae were added until prawns grew to the post-larval stage.

\section{Preparation and Treatment of Chemicals}

A stock solution of $10 \mathrm{mg} / \mathrm{mL}$ MF (Echelon Bioscience, Salt Lake City, UT, USA) was dissolved in 100\% ethanol (EtOH, Wako Pure 


\section{A MF effects on survival}

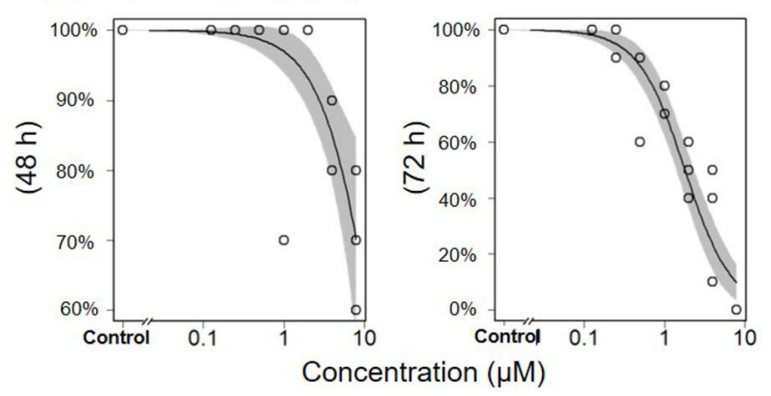

B EC $_{50} \mathrm{~s}$ of MF on survival

\begin{tabular}{|c|c|c|c|}
\hline Period & EC $_{\mathbf{5 0}}(\mathbf{\mu M})$ & Lower $(\mathbf{9 5 \%} \mathbf{C l})$ & Upper $\mathbf{( 9 5 \%} \mathbf{~ C l})$ \\
\hline $48 \mathrm{~h}$ & 7.67 & 6.20 & 9.14 \\
\hline $72 \mathrm{~h}$ & 1.74 & 1.33 & 2.15 \\
\hline
\end{tabular}

C MF effects on metamorphosis

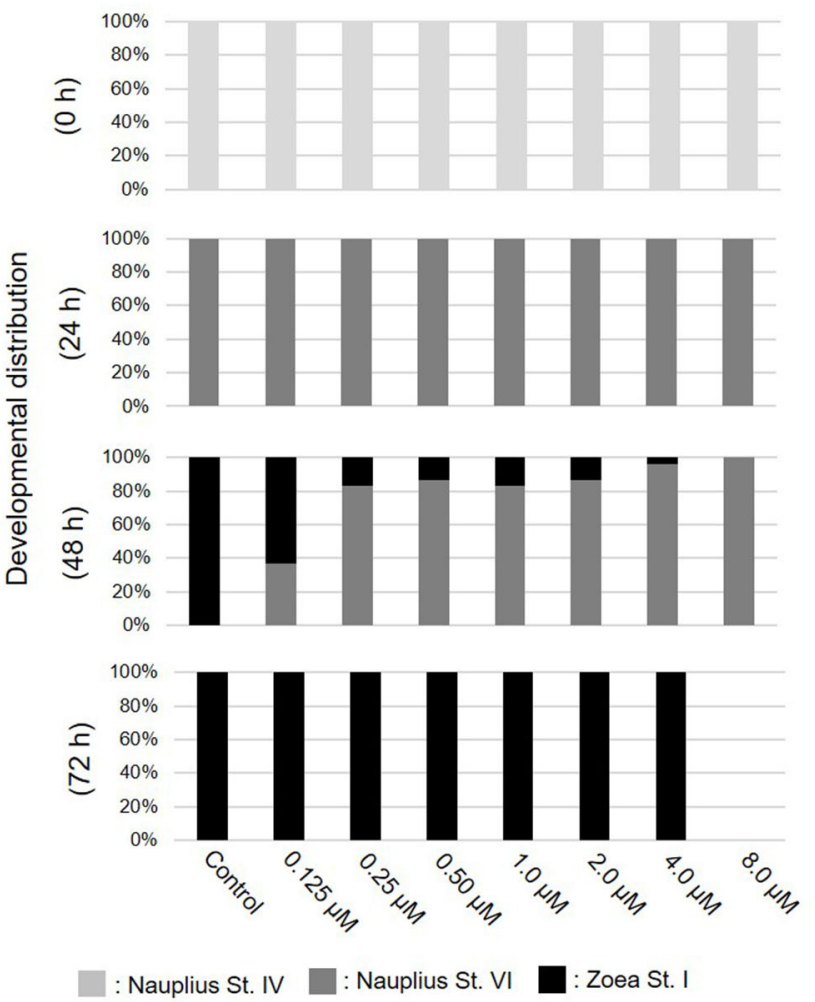

FIGURE 1 | Effects of MF treatment on nauplius stage IV. Regression curves of survival rate at 48 and $72 \mathrm{~h}$ (A). Gray shade indicates $95 \%$ confidence interval. Each $\mathrm{EC}_{50}$ value of survival rate at 48 and $72 \mathrm{~h}$ (B). Metamorphosis rates after exposure to MF at $0,24,48$, and $72 \mathrm{~h}$ (C).

Chemical Industries Ltd., Osaka, Japan) and kept at $-20^{\circ} \mathrm{C}$ until use. Based on this stock solution, a dilution series was prepared, as follows: $5.0,2.5,1.25,0.625$, and $0.3125 \mathrm{mg} / \mathrm{mL}$. These stock solutions were directly added to $500 \mathrm{~mL}$ of natural seawater containing 10 individuals each. Likewise, a stock of $100 \mathrm{mg} / \mathrm{mL}$ 20E (Sigma-Aldrich, St. Louis, MO, USA) was dissolved in $100 \%$ EtOH and kept at $-20^{\circ} \mathrm{C}$ until use. A second dilution series was prepared as follows: 50, 25, 12.5, 6.25, and $3.125 \mathrm{mg} / \mathrm{mL}$. These stock solutions were directly added to $500 \mathrm{~mL}$ of natural seawater containing 10 individuals each. Beakers were prepared in triplicate for each condition.

The final concentrations of MF for nauplius stage IV were $32.0,16.0,8.0,4.0,2.0,1.0,0.5,0.25,0.125 \mu \mathrm{M}$. Then, based on result of nauplius experiment, the range of concentrations of experiment of both zoea stage III and mysis stage III was decided as 2.0, 1.0, 0.5, and 0.25 $\mu \mathrm{M}$. Similarly, the final concentrations of $20 \mathrm{E}$ for nauplius stage IV were 16.0, 8.0, 4.0, 4.0, 2.0, 1.0, 0.5, 0.25, 0.125 , and $0.0625 \mu \mathrm{M}$, and for both zoea stage III and mysis stage III, they were $2.0,1.0,0.5$, and $0.25 \mu \mathrm{M}$.

After $24 \mathrm{~h}$, starting from hatching, most prawns grow to nauplius stage IV. Those were exposed to MF or 20E, and mortality, molting, and metamorphosis (from nauplius stage VI to zoea stage I) were recorded for $72 \mathrm{~h}$. The half maximal effective concentrations $\left(\mathrm{EC}_{50}\right)$ and $95 \%$ confidence interval
(CI) of mortality and metamorphosis rates of tested chemicals were calculated using R software (19). All data is available upon request.

\section{RESULTS}

\section{Effects of MF and 20E on the Nauplius Stage}

Treatment of nauplius stage IV prawns with either MF or $20 \mathrm{E}$ caused a dose-dependent decline in survival rates, and $\mathrm{EC}_{50}$ values at $72 \mathrm{~h}$ were apparently lower (MF: $1.74 \mu \mathrm{M}$; 20E: $0.29 \mu \mathrm{M})$ than at $48 \mathrm{~h}(\mathrm{MF}: 7.67 \mu \mathrm{M} ; 20 \mathrm{E}: 3.84 \mu \mathrm{M})$ (Figures 1A,B, 2A,B). In the solvent control group, metamorphic transitions from nauplius stage VI to zoea stage I occurred within $48 \mathrm{~h}$, but metamorphosis was delayed in a dose-dependent manner in both MF and 20E treatment groups (Figures 1C, 2C). The $\mathrm{EC}_{50}$ values of metamorphosis for $\mathrm{MF}$ and $20 \mathrm{E}$ were 0.12 (95\% CI: $0.05-0.20$ ) and 0.06 (95\% CI: 0.04-0.07) $\mu \mathrm{M}$, respectively. No metamorphosis took place after exposure to $8.0 \mu \mathrm{M} \mathrm{MF}$ and $>2.0 \mu \mathrm{M} 20 \mathrm{E}$. All individuals that died during this experiment were exclusively nauplius at stage VI. Moreover, transitions from nauplius stage IV to stage VI occurred at $24 \mathrm{~h}$ after initial exposure in all treatment groups (Figures 1C, 2C). 


\section{A 20E effects on survival}

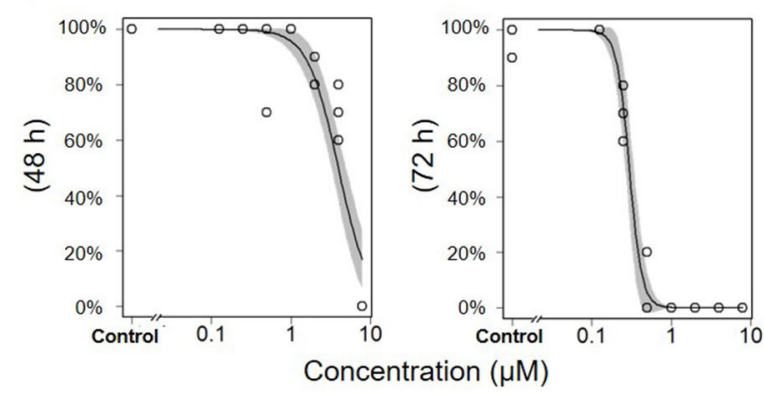

B $\mathrm{EC}_{50} \mathrm{~S}$ of $20 \mathrm{E}$ on survival

Period EC50 ( $\mu$ M) Lower (95\% Cl) Upper (95\% Cl)

\begin{tabular}{|l|l|l|l|}
\hline $48 \mathrm{~h}$ & 3.84 & 3.10 & 4.57 \\
\hline $72 \mathrm{~h}$ & 0.29 & 0.24 & 0.33 \\
\hline
\end{tabular}

C 20E effects on metamorphosis

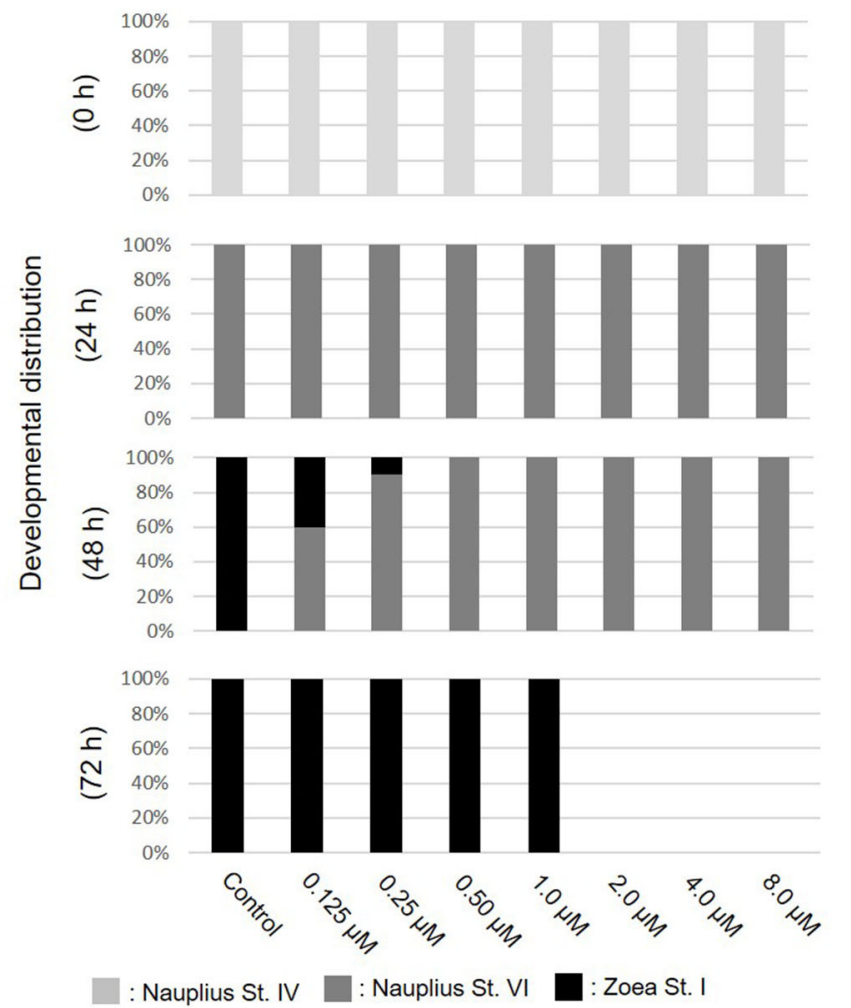

FIGURE 2 | Effects of 20E treatment on nauplius stage IV. Regression curves of survival rate at 48 and $72 \mathrm{~h}$ (A). Gray shade indicates $95 \%$ confidence interval. Each $\mathrm{EC}_{50}$ value of survival rate at 48 and $72 \mathrm{~h}$ (B). Metamorphosis rates after exposure to $20 \mathrm{E}$ at $0,24,48$, and $72 \mathrm{~h}$ (C).

The results show that $20 \mathrm{E}$ was more toxic than MF to the nauplius stage in terms of the rate of mortality and metamorphosis.

\section{Effects of MF and 20E on the Zoea Stage}

When the zoea larvae at stage III were exposed to a concentration series of MF or 20E, survival ratios decreased sharply in a dosedependent manner at $48 \mathrm{~h}$ (Figures 3A,D). The $\mathrm{EC}_{50}$ values of survivability of zoea larvae for MF and 20E were $1.25(95 \%$ CI: $0.99-1.52)$ and 0.22 (95\% CI: $0.10-0.33) \mu \mathrm{M}$, respectively (Figures 3B,E). Although the metamorphic transition from zoea to mysis occurs normally within $48 \mathrm{~h}$, no metamorphic transition occurred in the $20 \mathrm{E}$ treatment at more than $0.5 \mu \mathrm{M}$, unlike in the MF treatment groups (Figures 3C,F), and all individuals that died were zoea at stage III, except for the $2.0 \mu \mathrm{M}$ MF treatment group.

\section{Effects of MF and 20E on the Mysis Stage}

When mysis larvae at stage III were exposed to a concentration series of MF or 20E, survival ratios decreased dose-dependently at 48 and at $24 \mathrm{~h}$, respectively (Figure 4 ). The $\mathrm{EC}_{50}$ values of $48 \mathrm{~h}$ survivability of mysis lavae for MF and 20E were 0.65 (95\% CI: $0.46-0.83)$ and $0.46(95 \% \mathrm{CI}: 0.34-0.59) \mu \mathrm{M}$, respectively (Figures 4B,E). Even though the metamorphic transition from mysis to post-larvae occurs normally within $48 \mathrm{~h}$, there was a dose-dependent decrease in metamorphic rate in response to MF treatments. In contrast, post-larvae were found in the $20 \mathrm{E}$ concentration series. No prawns survived exposure to $2.0 \mu \mathrm{M}$ of either MF or 20E (Figures 4C,F). All individuals that died during this experiment were stage III mysis.

\section{DISCUSSION}

This study demonstrated that exogenous treatment of either MF or $20 \mathrm{E}$ to larval stages of kuruma prawn caused the retardation of molting associated with metamorphosis and a decline in survivability of larvae in a dose-dependent manner. Interestingly, $\mathrm{EC}_{50}$ values at $48 \mathrm{~h}$ after the exposure to these compounds indicated that $20 \mathrm{E}$ more effectively decreased survivability and delayed metamorphosis than MF (Figure 5). At the nauplius stage, there were the huge gaps in $\mathrm{EC}_{50}$ values between survival and metamorphosis in both MF and 20E treatments. However, each $\mathrm{EC}_{50}$ value between $\mathrm{MF}$ and $20 \mathrm{E}$ was very consistent when transitions occurred from zoea to mysis, and from mysis to post-larva (Figure 5). These findings suggest that nauplius larvae have higher tolerance against the lethal effect of MF and $20 \mathrm{E}$ than other stages (e.g., zoea and mysis), and that there are different endocrine cassettes regulating transition from nauplius to zoea and later metamorphosis (zoea to mysis, 


\section{A MF effect on survival}

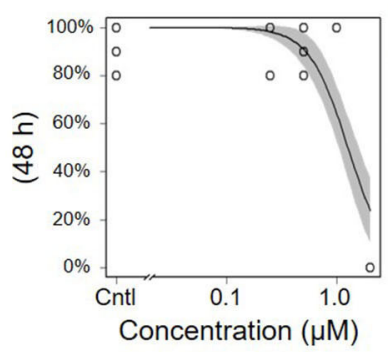

\section{MF effect on metamorphosis}
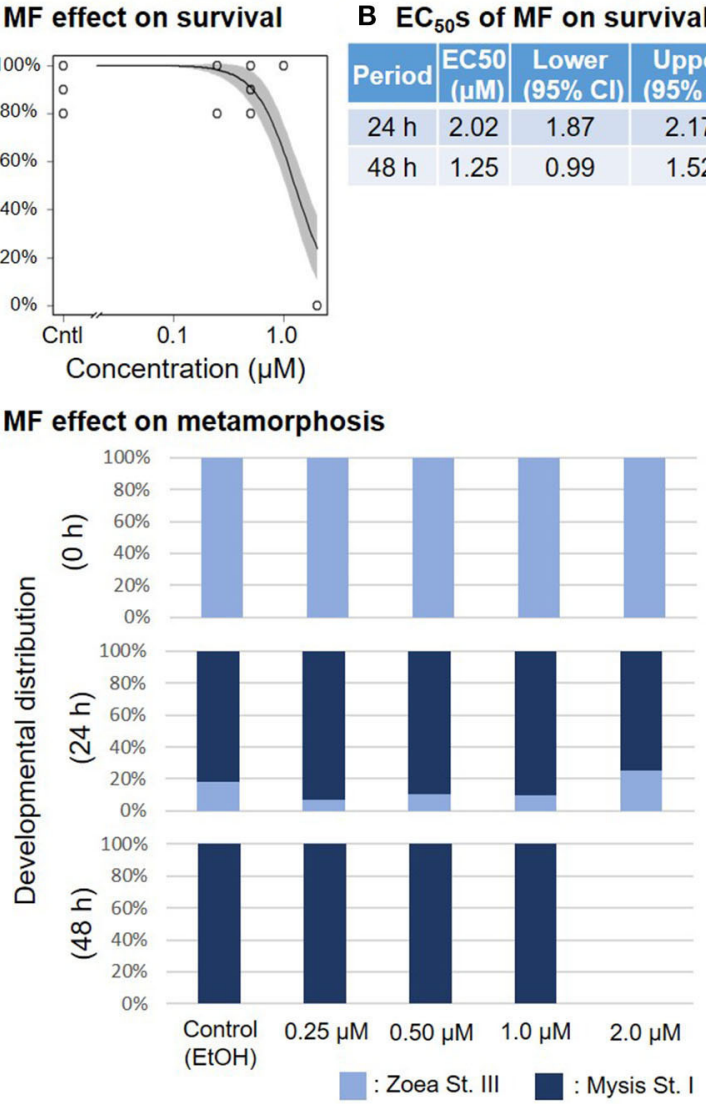

D 20 E effect on survival
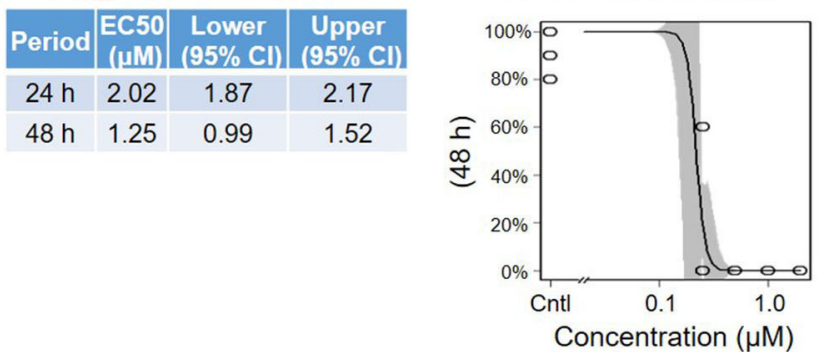

E $E_{50}$ s of $20 E$ on survival

\begin{tabular}{|c|c|c|c|}
\hline Period & $\begin{array}{c}\text { EC50 } \\
(\mathbf{u M})\end{array}$ & $\begin{array}{c}\text { Lower } \\
(95 \% \mathrm{Cl})\end{array}$ & $\begin{array}{c}\text { Upper } \\
(9.5 \% \mathrm{Cl})\end{array}$ \\
\hline $24 \mathrm{~h}$ & $\mathrm{NA}$ & NA & NA \\
\hline $48 \mathrm{~h}$ & 0.22 & 0.10 & 0.33 \\
\hline
\end{tabular}

\begin{tabular}{l|l|l}
$48 \mathrm{~h}$ & 0.22 & 0.10
\end{tabular}

0.33

\section{F 20E effects on metamorphosis}

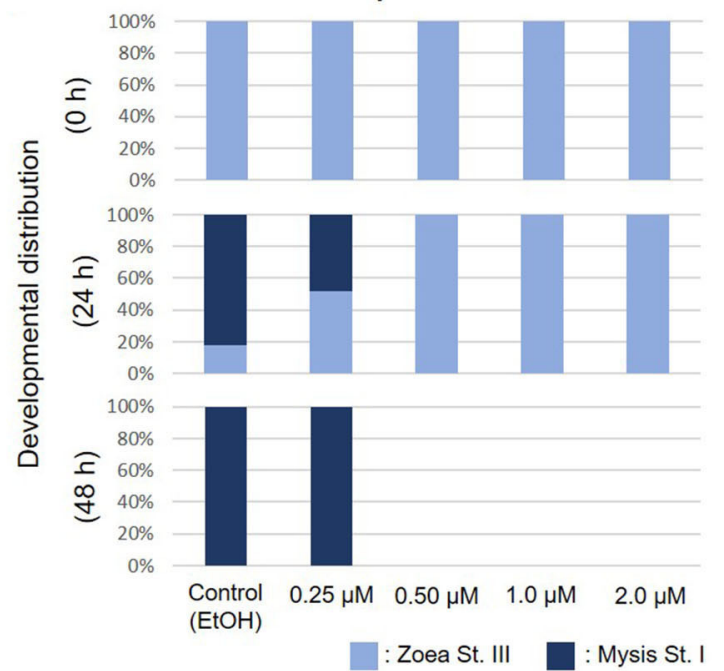

FIGURE 3 | Effects of MF and 20E treatments on zoea stage III. Regression curves of survival rate at 48 and $72 \mathrm{~h}$ in response to MF and $20 \mathrm{E}$ treatments (A,D). Gray shades indicate $95 \%$ confidence intervals. $\mathrm{EC}_{50}$ values of MF and $20 \mathrm{E}$ treatments (B,E). Metamorphosis rates after exposure to $\mathbf{M F}$ and $20 \mathrm{E}$ at 0,24 , and $48 \mathrm{~h}$ (C,F).

and mysis to post larvae stages). In terms of the effects of MF on larval development and metamorphosis, some studies have reported similar results, such as the administration of MF, which delayed larval development and metamorphosis in freshwater prawn (Macrobrachium rosenbergii) (20, 21), or MF treatment, which induced precocious metamorphosis in the barnacle (Balanus amphitrite) (22, 23). Likewise, the precise regulation of the endogenous level of $20 \mathrm{E}$ plays a key role in the success of molting. Supporting evidence from various crustaceans consistently suggests that a pulse of the endogenous $20 \mathrm{E}$ titer is required for a complete molting cycle $(12,24)$.

Our data showed that either exogenous MF or 20E treatment to kuruma prawn larvae decreased the survival rate, and retarded larval development and metamorphosis. The $\mathrm{EC}_{50}$ values that we observed were similar to those in previous studies using the freshwater tiny crustacean (Daphnia magna), which is a well-known environmental indicator. For example, mortality in response to $20 \mathrm{E}$ treatment occurred with $5.119 \mu \mathrm{M}$ (25), and males were induced by treatment with $0.278 \mu \mathrm{M} \mathrm{MF}$ (26). Moreover, using chemically-synthesized insecticides with MF- or 20E-like bioactivity, many studies investigated their endocrine-disrupting effects in various crustaceans. In the mud crab ( $R$. harrisii), treatment with $0.159 \mu \mathrm{M}$ fenoxycarb reduced survival and extended the duration of larval metamorphosis from zoea to megalopa (27). The $\mathrm{LC}_{50}$ (50\% lethal concentration) values at $24 \mathrm{~h}$ for fenoxycarb and methoprene, two JH-mimicking chemicals, were 4.74 and $6.31 \mu \mathrm{M}$, respectively (at $48 \mathrm{~h}$, values were 3.52 and $4.48 \mu \mathrm{M}$ ), in the cherry shrimp (Neocaridina davidi) (28). Natural concentrations of methoprene in freshwater have typically ranged from 3.0 to $30.0 \mathrm{nM}(29,30)$, suggesting that IGRs with $\mathrm{JH}$-activity might have toxic effects on crustacean development in wild populations. Similarly, treatment with 3.37-33.7 $\mu \mathrm{M}$ of RH 5849 (1,2-dibenzoyl,1-t-butyhly drazine), which has IGR-bearing ecdysteroid activity, accelerated larval molting in the crab ( $R$. harrisii) and enhanced attachment and metamorphosis in the barnacle (B. amphitrite) (31), while exogenous treatment with $0.5 \mu \mathrm{M} 20 \mathrm{E}$ inhibited molting and ovulation in the water flea (D. magna) (32). Taken together with findings in other crustaceans, the present study demonstrates that larval development in the kuruma prawn may be highly sensitive to MF- and 20E-like chemicals. In addition to short-term assay, the long-term (chronic) assay will be more clearly demonstrated that impacts of those chemical exposure on larval development of kuruma prawn in the ecological point of view.

Recent advances in omics approaches enable the depiction of the expression pattern of many genes and to estimate the 


\section{A MF effect on survival}

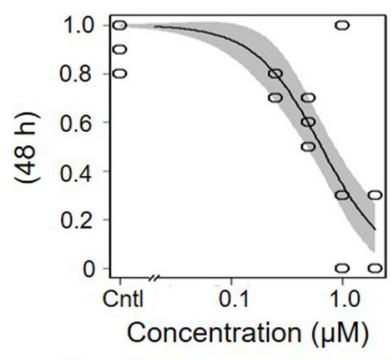

C MF effects on metamorphosis

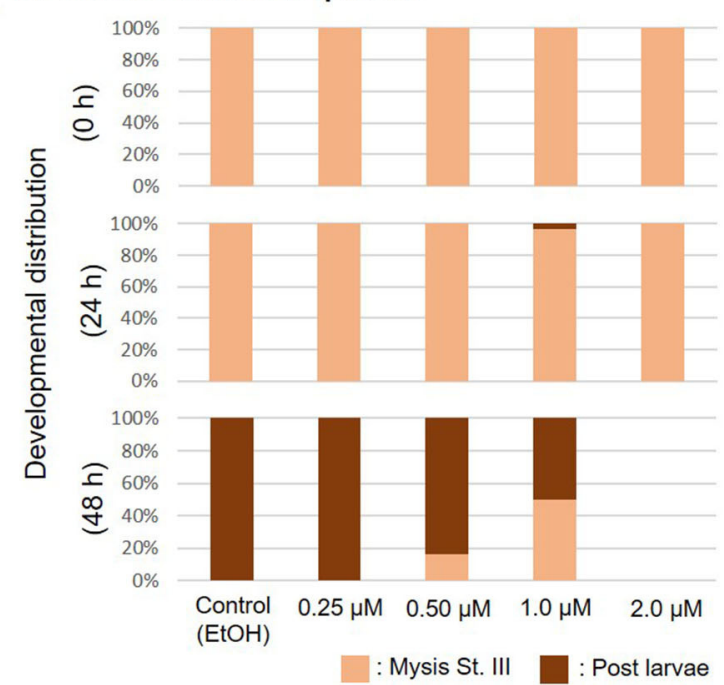

D 20E effect on survival

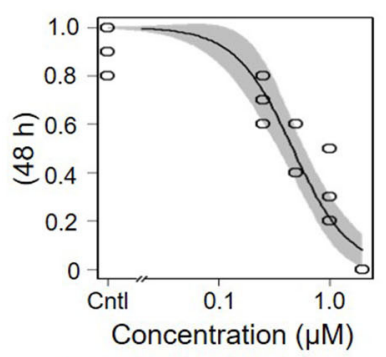

\section{F 20E effects on metamorphosis}

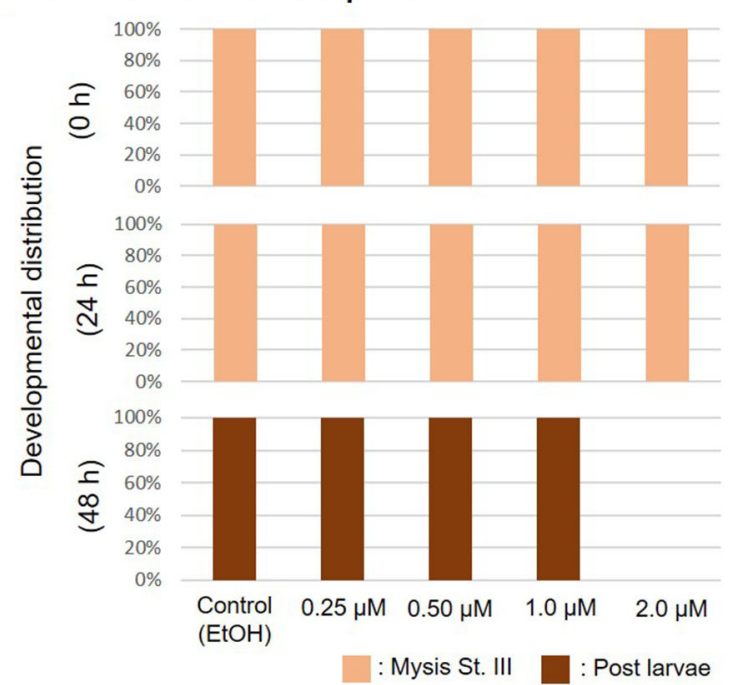

FIGURE 4 | Effects of MF and 20E treatments on mysis stage III. Regression curves of survival rate at 48 and $72 \mathrm{~h}$ in response to MF and $20 \mathrm{E}$ treatments (A,D). Gray shades indicate $95 \%$ confidence intervals. $\mathrm{EC}_{50}$ values of MF and $20 \mathrm{E}$ treatments (B,E). Metamorphosis rates after exposure to MF and $20 \mathrm{E}$ at 0,24 , and $48 \mathrm{~h}$ (C),F).

regulatory interactions involved in metamorphosis in the prawn (M. rosenbergii) (33), the shrimp (Neocaridina denticulata) (34), and the spiny lobster (Sagmariasus verreauxi) $(35,36)$. Although the aforementioned transcriptome studies provided various new insights, the number of unannotated genes has hampered the completion of more comprehensive analysis due to the lack of publicly available genomes. To address this resource problem, the complete genome of the Pacific white shrimp (Litopenaeus vannamei) was decoded, providing a new hypothesis of the regulatory mechanisms underlying adult molting via sterol regulatory elements (SRE)-binding protein and opsin (37). In addition to next generation sequencing, mass spectrometry technology (e.g., LC- and GC-MS) has allowed the metabolite profiling (38), and quantification of endogenous juvenoid in hemolymph of freshwater prawn M. rosenbergii (39) and ecdysteroid titers in the extracts of tiny crustaceans (40, 41 ), enabling the monitoring of the pulse (rise and decline) of those hormones during metamorphosis. It will be necessary to elucidate the fluctuating dynamics of MF and 20E titers during larval development in kuruma prawn. Some advanced studies found that this can be successfully achieved by integrating the data acquired from in vivo pharmacological assays and omics approaches $(28,42,43)$, suggesting that this approach will be applied for comprehensively understanding the mechanisms of diversified crustacean metamorphosis. Additionally, treatments of those inhibitors/antagonists will be useful for understanding their physiological function. Indeed, the fenarimol, which is an inhibitor of ecdysteroid synthesis, could be applied in the molting research, because it has been used in Daphnia (40). Although less is known about the inhibitor/antagonist of $\mathrm{JH}$, some potential $\mathrm{JH}$ antagonists have been identified using the yeast two-hybrid system transformed with the mosquito $\mathrm{JH}$ receptor as a reporter system (44).

In conclusion, we conducted laboratory experiments to investigate the toxic effects of $\mathrm{MF}$ and $20 \mathrm{E}$ using larval stages of the kuruma prawn. We demonstrated that both MF and $20 \mathrm{E}$ induced high mortality caused by disruption of moltingassociated metamorphosis, although the nauplius showed strong resistance to $\mathrm{MF}$ and $20 \mathrm{E}$. This is the first experimental evidence of the in vivo physiological functions of $\mathrm{MF}$ and $20 \mathrm{E}$ in the larval stages of kuruma prawn, shedding light on not only the ecotoxicological impacts of IGRs released into nature, but also on the endocrine mechanisms underlying larval development with metamorphosis in benthic decapod crustaceans. 


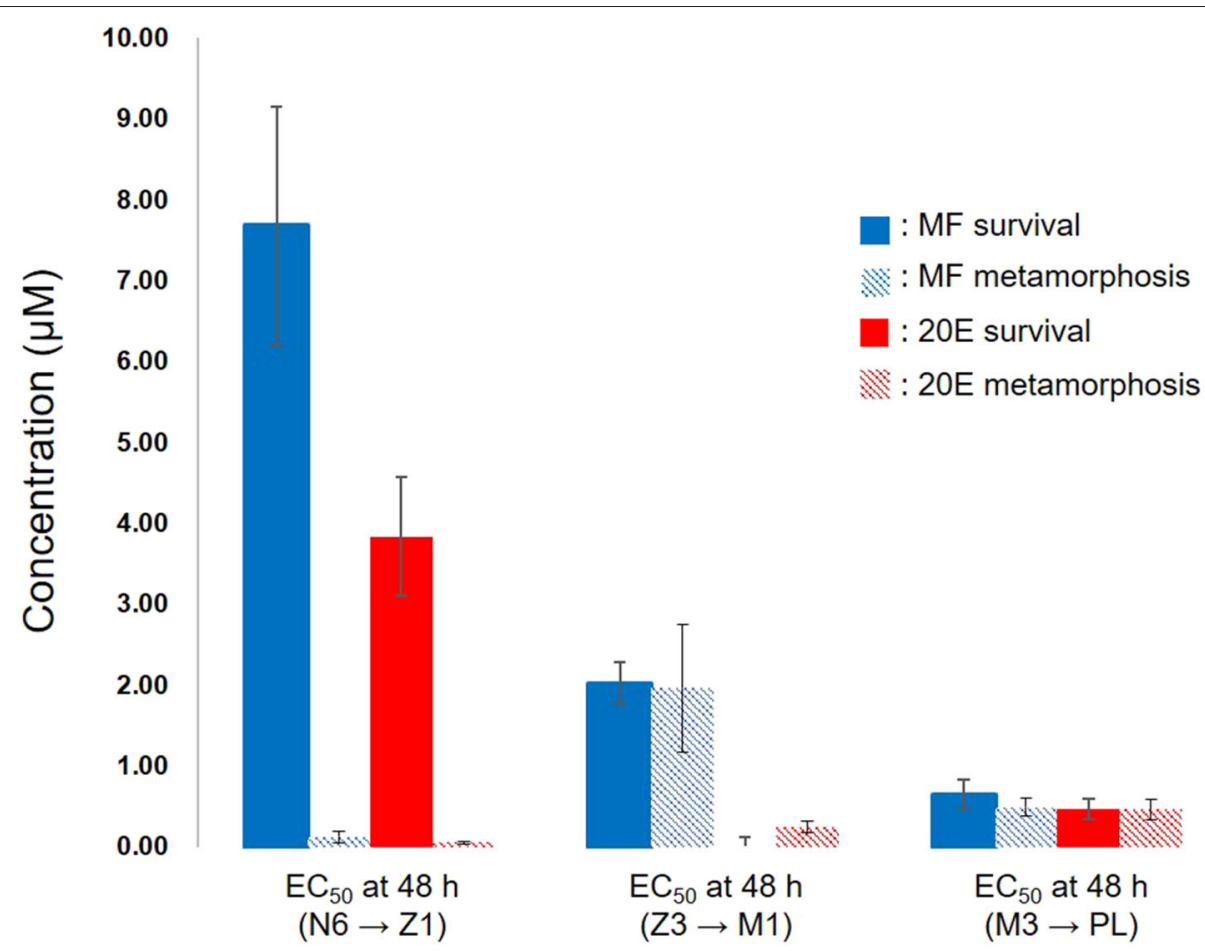

FIGURE 5 | Relationships between $\mathrm{EC}_{50}$ of survivability and metamorphosis at $48 \mathrm{~h}$ after exposure of MF and 20E. N6, nauplius stage Vl; Z1, zoea stage I; Z3, zoea stage III; M1, mysis stage I; M3, mysis stage III; PL, post-larvae. Error bars indicate 95\% confidence intervals. NA indicates that data is not available.

\section{DATA AVAILABILITY STATEMENT}

The raw data supporting the conclusions of this article will be made available by the authors, without undue reservation.

\section{AUTHOR CONTRIBUTIONS}

$\mathrm{KT}$ and TO designed all experiments in this study. KT and FY conducted all experiments and obtained all raw data. KT conducted all data analyses and prepared the first draft of the paper. All authors contributed to the article and approved the submitted version.

\section{FUNDING}

This work was partially supported by the Japan Society for the Promotion of Science (JSPS), Research Fellowship for Young

\section{REFERENCES}

1. Oakley TH, Wolfe JM, Lindgren AR, Zaharoff AK. Phylotranscriptomics to bring the understudied into the fold: monophyletic ostracoda, fossil placement, and pancrustacean phylogeny. Mol Biol Evol. (2013) 30:215-33. doi: $10.1093 / \mathrm{molbev} / \mathrm{mss} 216$

2. Miyakawa H, Toyota K, Sumiya E, Iguchi T. Comparison of JH signaling in insects and crustaceans. Curr Opin Insect Sci. (2014) 1:81-7. doi: 10.1016/j.cois.2014.04.006
Scientists 12J05579 to KT, KAKENHI Grant $15 \mathrm{H} 06839$ to KT, and the Japan Prize Foundation in 2019 to KT.

\section{ACKNOWLEDGMENTS}

We are grateful to Dr. Suitoh Katsuyoshi, Aichi Fishing Farming Institute, for his kind support with supply of kuruma prawn larvae, and Mrs. Kazunori Uetani, Yoshinori Nishi, Atsushi Hamabe, Hiroya Fujioka, and Kusukiyo Okamoto, and Mmes. Sayuki Yamamoto, Chiaki Nakamura, Natsuki Ida, Miwa Shibahara, Mie Prefectural Fish Farming Center, for their kind assistance during the rearing experiment, and Mr. Naoshi Satonaka, Towa Electronic Co., Ltd., for his kind support of daily life (KT) during the experiment at Mie Prefectural Fish Farming Center. We thank Prof. Taisen Iguchi, Yokohama City University, for critically reading the manuscript. 
farnesoic acid stimulation of vitellogenin gene expression. Mol Reprod Dev. (2005) 70:288-300. doi: 10.1002/mrd.20213

6. Charles JP, Iwema T, Epa VC, Takaki K, Rynes J, Jindra M. Ligand-binding properties of a juvenile hormone receptor, Methoprene-tolerant. Proc Natl Acad Sci USA. (2011) 108:21128-33. doi: 10.1073/pnas.1116123109

7. Kato Y, Kobayashi K, Oda S, Tatarazako N, Watanabe H, Iguchi T. Cloning and characterization of the ecdysone receptor and ultraspiracle protein from the water flea Daphnia magna. J Endocrinol. (2007) 193:183-94. doi: 10.1677/JOE-06-0228

8. Li M, Mead EA, Zhu JS. Heterodimer of two bHLH-PAS proteins mediates juvenile hormone-induced gene expression. Proc Natl Acad Sci USA. (2011) 108:638-43. doi: 10.1073/pnas.1013914108

9. Miyakawa H, Toyota K, Hirakawa I, Ogino Y, Miyagawa S, Oda S, et al. A mutation in the receptor Methoprene-tolerant alters juvenile hormone response in insects and crustaceans. Nat Commun. (2013) 4:1856. doi: $10.1038 /$ ncomms 2868

10. Zhang ZL, Xu JJ, Sheng ZT, Sui YP, Palli SR. Steroid receptor coactivator is required for juvenile hormone signal transduction through a bHLHPAS transcription factor, methoprene tolerant. J Biol Chem. (2011) 286:8437-47. doi: 10.1074/jbc.M110.191684

11. Miyakawa H, Sato T, Song Y, Tollefsen KE, Iguchi T. Ecdysteroid and juvenile hormone biosynthesis, receptors and their signaling in the freshwater microcrustacean Daphnia. J Steroid Biochem Mol Biol. (2018) 184:62-8. doi: 10.1016/j.jsbmb.2017.12.006

12. Song Y, Villeneuve DL, Toyota K, Iguchi T, Tollefsen KE. Ecdysone receptor agonism leading to lethal molting disruption in arthropods: review and adverse outcome pathway development. Environ Sci Technol. (2017) 51:414257. doi: 10.1021/acs.est.7b00480

13. Laufer HD, Borst F, Baker C, Carrasco M, Sinkus C, Reuter LT, et al. Identification of a juvenile hormone-like compound in a crustacean. Science. (1987) 235:202-5. doi: 10.1126/science.235.4785.202

14. Nakatsuji T, Lee CY, Watson D. Crustacean molt-inhibiting hormone: structure, function, and cellular mode of action. Comp Biochem Physiol A Mol Integr Physiol. (2009) 152:139-48. doi: 10.1016/j.cbpa.2008.10.012

15. Dan S, Kaneko T, Takeshima S, Ashisate M, Hamasaki K. Eyestalk ablation affects larval morphogenesis in the swimming crab Portunus trituberculatus during metamorphosis into megalopae. Sex Early Dev Aquat Org. (2014) 1:57-73. doi: $10.3354 /$ sedao00007

16. Holthuis LB. FAO species catalogue., vol. 1 Shrimps and prawns of the world. An annotated catalogue of species of interest to fisheries. FAO Fish Synop. (1980) 125:46.

17. Hamasaki K, Kitada S. Catch fluctuation of Kuruma prawn, Penaeus japonicus in Japan relative to ocean climate variability and a stock enhancement program. Rev Fish Sci. (2013) 21:454-68. doi: 10.1080/10641262.2013.800781

18. Hamasaki K, Kitada S. A review of kuruma prawn Penaeus japonicus stock enhancement in Japan. Fish Res. (2006) 80:80-90. doi: 10.1016/j.fishres.2006.03.018

19. R Core Team. R: A Language and Environment for Statistical Computing. Vienna: R Foundation for Statistical Computing (2019). Available online at: https://www.R-project.org/

20. Abdu U, Takac P, Hans L, Sagi A. Effect of methyl farnesoate on late larval development and metamorphosis in the prawn Macrobrachium rosenbergii (Decapoda, Palaemonidae): a juvenoid-like effect? Biol Bull. (1998) 195:112-9. doi: $10.2307 / 1542818$

21. Abdu U, Takac P, Yehezkel G, Chayoth R, Sagi A. Administration of methyl farnesoate through the artemia vector, and its effect on Macrobrachium rosenbergii larvae. Israel J Aquac. (1998) 50:73-81.

22. Smith PA, Clare AS, Rees HH, Prescott MC, Wainwright G, Thorndyke MC. Identification of methyl farnesoate in the cypris larva of the barnacle, Balanus amphitrite, and its role as a juvenile hormone. Insect Biochem Mol Biol. (2000) 30:885-90. doi: 10.1016/S0965-1748(00)0 0062-X

23. Yamamoto H, Okino T, Yoshimura E, Tachibana A, Shimizu K, Fusetani N. Methyl farnesoate induces larval metamorphosis of the barnacle, Balanus amphitrite via protein kinase C activation. J Exp Zool. (1997) 278:349-55. doi: 10.1002/(SICI)1097-010X(19970815)278:6<349::AID-JEZ2>3.0.CO;2-O
24. Chang ES, Mykles DL. Regulation of crustacean molting: a review and our perspectives. Gen Comp Endocrinol. (2011) 172:323-30. doi: 10.1016/j.ygcen.2011.04.003

25. Baldwin WS, Bailey B, Long KE, Klaine S. Incomplete ecdysis is an indicator of ecdysteroid exposure in Daphnia magna. Environ Toxicol Chem. (2001) 20:1564-9. doi: 10.1002/etc.5620200721

26. Tatarazako N, Oda S, Watanabe H, Morita M, Iguchi T. Juvenile hormone agonists affect the occurrence of male Daphnia. Chemosphere. (2003) 53:82733. doi: 10.1016/S0045-6535(03)00761-6

27. Cripe GM, McKenney CL Jr, Hoglund MD, Harris PS. Effects of fenoxycarb exposure on complete larval development of the xanthid crab, Rhithropanopeus harrisii. Environ Pollut. (2003) 125:295-9. doi: 10.1016/S0269-7491(02)00414-1

28. Hu XL, Niu JJ, Meng Q, Chai YH, Chu KH, Chan KM. Effects of two juvenile hormone analogue insecticides, fenoxycarb and methoprene, on Neocaridina davidi. Environ Pollut. (2019) 253:89-99. doi: 10.1016/j.envpol.2019.06.120

29. Olmstead AW, LeBlanc GL. Low exposure concentration effects of methoprene on endocrine-regulated processes in the crustacean Daphnia magna. Toxicol Sci. (2001) 62:268-73. doi: 10.1093/toxsci/62.2.268

30. Ross DH, Judy D, Jacobson B, Howell R. Methoprene concentrations in freshwater microcosms treated with sustained-release Al- tosid7 formulations. J Amer Mosq Control Assoc. (1994) 10:202-10.

31. Clare AS, Rittschof D, Costlow JDJr. Effects of the nonsteroidal ecdysone mimic RH 5849 on larval crustaceans. J Exp Zool. (1992) 262:436-40. doi: $10.1002 /$ jez.1402620410

32. Sumiya E, Ogino $\mathrm{Y}$, Hiruta C, Toyota K, Miyagawa S, Iguchi $\mathrm{T}$. Roles of ecdysteroids for progression of reproductive cycle in the fresh water crustacean Daphnia magna. Front Zool. (2014) 11:60. doi: 10.1186/s12983-014-0060-2

33. Ventura T, Manor R, Aflalo ED, Chalifa-Caspi V, Weil S, Sharabi O, et al. Post-embryonic transcriptomes of the prawn Macrobrachium rosenbergii: multigenic succession through metamorphosis. PLoS ONE. (2013) 8:e55322. doi: 10.1371/journal.pone.0055322

34. Sin YW, Kenny NJ, Qu Z, Chan KW, Chan KW, Cheong SP, et al. Identification of putative ecdysteroid and juvenile hormone pathway genes in the shrimp Neocaridina denticulata. Gen Comp Endocrinol. (2015) 214:16776. doi: 10.1016/j.ygcen.2014.07.018

35. Ventura T, Fitzgibbon QP, Battaglene SC, Elizur A. Redefining metamorphosis in spiny lobsters: molecular analysis of the phyllosoma to puerulus transition in Sagmariasus verreauxi. Sci Rep. (2015) 5:13537. doi: 10.1038/srep13537

36. Ventura T, Bose U, Fitzgibbon QP, Smith GG, Shaw PN, Cummins $\mathrm{SF}$, et al. CYP450s analysis across spiny lobster metamorphosis identifies a long sought missing link in crustacean development. $J$ Steroid Biochem Mol Biol. (2017) 171:262-9. doi: 10.1016/j.jsbmb.2017. 04.007

37. Zhang X, Yuan J, Sun Y, Li S, Gao Y, Yu Y, et al. Penaeid shrimp genome provides insights into benthic adaptation and frequent molting. Nat Commun. (2019) 10:356. doi: 10.1038/s41467-01808197-4

38. Toyota K, Gavin A, Miyagawa S, Viant MR, Iguchi T. Metabolomics reveals an involvement of pantothenate for male production responding to the shortday stimulus in the water flea, Daphnia pulex. Sci Rep. (2016) 6:25125. doi: 10.1038/srep25125

39. Wilder MN, Okada S, Fusetani N, Aida K. Hemolymph profiles of juvenoid substances in the giant freshwater prawn Macrobrachium rosenbergii in relation to reproduction and molting. Fish Sci. (1995) 61:175-6. doi: $10.2331 /$ fishsci.61.175

40. Sumiya E, Ogino Y, Toyota K, Miyakawa H, Miyagawa S, Iguchi T. Neverland regulates embryonic moltings through the regulation of ecdysteroid synthesis in the water flea Daphnia magna, and may thus act as a target for chemical disruption of molting. J Appl Toxicol. (2016) 36:1476-85. doi: 10.1002/jat. 3306

41. Montes R, Rodil R, Neuparth T, Santos MM, Cela R, Quintana JB. A simple and sensitive approach to quantify methyl farnesoate in whole arthropods by matrix-solid phase dispersion and gas chromatography-mass spectrometry. J Chromatogr A. (2017) 1508:158-62. doi: 10.1016/j.chroma.201 7.06 .001 
42. Abe R, Toyota K, Miyakawa H, Watanabe H, Oka T, Miyagawa S, et al. Diofenolan induces male offspring production through binding to the juvenile hormone receptor in Daphnia magna. Aquat Toxicol. (2015) 159:44-51. doi: 10.1016/j.aquatox.2014.11.015

43. Toyota K, Kato Y, Miyakawa H, Yatsu R, Mizutani T, Ogino Y, et al. Molecular impact of juvenile hormone agonists on neonatal Daphnia magna. J Appl Toxicol. (2014) 34:537-44. doi: 10.1002/jat.2922

44. Lee SH, Oh HW, Fang Y, An SB, Park DS, Song HH, et al. Identification of plant compounds that disrupt the insect juvenile hormone receptor complex. Proc Natl Acad Sci USA. (2015) 112:1733-8. doi: 10.1073/pnas.14243 86112
Conflict of Interest: The authors declare that the research was conducted in the absence of any commercial or financial relationships that could be construed as a potential conflict of interest.

Copyright (C) 2020 Toyota, Yamane and Ohira. This is an open-access article distributed under the terms of the Creative Commons Attribution License (CC BY). The use, distribution or reproduction in other forums is permitted, provided the original author(s) and the copyright owner(s) are credited and that the original publication in this journal is cited, in accordance with accepted academic practice. No use, distribution or reproduction is permitted which does not comply with these terms. 